were much prized by their owners, for the quality and temper of the steel, and much cost was lavished on the ornaments of the handles and sheaths. The making of a good sword was regarded as a very serious task, and the maker had to conform to certain rules of conduct from the commencement to the end of the operation. The external ornaments offered endless scope to the skill and care of the worker in metals. Great importance is attached to the maker's name, which is engraved above the guard. It was a common saying of the Japanese, that the swords of celebrated makers, such as Naminohira Yukiyasu, Masamune, and others, could not return to their scabbards, unless they had been dipped in blood; the sword maker's occupation is now gone, not so their fellow-artists, the sword-mounters. Their skill in working metals can always be turned to good account.

Many other works in metal in the gallery deserve mention, but we cannot refer to them here. They all exhibit the patience, skill, imagination, and love of his craft which distinguished the Japanese artist of old. It is to be feared that he is now abandoning these qualities, and seeking a more rapid road to fortune by shoddy foreign imitations, and that beautiful works requiring the patience and loving care of years-such, for instance, as the small cabinet shown in Grafton Street, which was made for the third Shôgun of the last dynasty, and which is probably the finest work of its kind in existence--will soon be things of the past.

\section{ELECTRICITY AT THE CRYSTAL PALACE} III. Land Telegraphy.

HAVING regard to the leading part played by our country in the rise and development of the telegraph, it was only to be expected that the display of historical apparatus at the Crystal Palace should be a very good one. Thanks to the antiquarian zeal of $\mathrm{Mr}$. W. H. Preece, F.R.S., and his active interest in all that pertains to the history of his profession, the Post Office has become the careful custodian of all the early telegraphs employed in England, and the stall of H.M. Postmaster General is rich in these relics of the past. Indeed, there is the nucleus here of an interesting museum of telegraphic apparatus; and it is to be hoped that such a museum will one day be established. The Society of Telegraph Engineers and Electricians have now their Ronald's Library of Electrical Works, which is practically open to all inquirers. A public museum of electrical appliances, rendered historical by the lapse of time, would be a supplementary institution of inestimable value.

One of the most interesting of these relics is the 1816 telegraph of Sir Francis Ronald himself, kindly lent by Mr. Latimer Clark, together with a portion of the copper conductor which Ronald threaded through a glass tube, protected by a wooden trough, and buried in his garlen at Hammersmith. It was a frictional electric telegraph, and indicated letters by the divergence of two pith balls, after a plan somewhat similar to the suggestion of "C.M." in the Scots Magazine for 1759. This device is fully described in Ronald's "Electrical Telegraph," I836, the first work published in England on the subject. A copy of this work is possessed by Mr. Latimer Clark, who we may also mention has lately acquired a forgotten book on the history of telegraphs (non-electrical), published in 1797 for the author, Mr. J. Gamble.

On August 5, 1816, the British Admiralty expressed their opinion to Sir Francis Ronalds that "telegraphs of any kind were then wholly unnecessary," and the invention of Ronalds was neglected. Nevertheless, being worked by static electricity, it is doubtful if it ever would have become a practical success. The "fossil" telegraph of Messrs. Cooke and Wheatstone, laid between Euston and Camden Town in 1837 , was the first practical telegraph in operation, and a specimen of it is shown by the
Post Cffice. The line was formed of copper wires covered with cotton and pitch, and inlaid in triangular lengths of wood, which were buried underground. It was worked in connection with Cooke and Wheatstone's Five Needle Telegraph, the parent of the present single and double needle instruments, now used in railway signalling.

Especiaily interesting also are the porcelain tubes employed by Samuel Morse as insulators, and the lead type, cast by that inventor as early as December, 1832, for his electromagnetic telegraph, now known as the Morse inker. The original Cooke and Wheatstone needle instruments, and the apparatus designed to compete with them, for example, Alexander Bain's I. and V. telegraph, in which the alphabet is formed by the movement of two pointers attached to circular magnets moving inside coils; the Highton gold leaf telegraph, in which a strip of gold leaf inclosed in a glass tube traverses the field of a permanent magnet, and forms part of the line-circuit. When a current passes through the leaf it moves to right or left, according to the polarity. Henley's Magneto Telegraph, the Wheatstone ABC instrument, and the Bell receiver of Sir Charles Bright, are also shown. This last appeals to the ear rather than the eye, by striking two bells of different pitch, and is the forerunner of the modern class of "sounders" which are superseding writing telegraphs on land-lines in America and England, owing to their clean and rapid working, and the ease with which a clerk can listen to the message and write it down at the same time.

Space would fail us if we were to refer to all the historical apparatus exhibited by the Post Office. There the visitor will be able to trace the development of the electric telegraph in this country from the earliest attempts, and on the same table he will see at work the latest improved apparatus for transmitting and receiving messages. The Wheatstone automatic instrument, which is capable of sending 200 words per minute, and is chiefly used for press intelligence, the American duplex, on the Morse system, and the Pneumatic Despatch, for forwarding written telegrams from St. Martins le Grand to local stations in the City, are all in operation.

Before leaving the Post Office stall we ought to mention an imported curiosity, which excited a great deal of interest when first displayed in the Norwegian Section of the recent Paris Electrical Exhibition, and to which we drew attention some months ago. This is a sample of a telegraph post from Norway, which has been pierced through and through by the beaks of the black and green Norwegian woodpeckers. Two of these marauders are stuffed and mounted on the perforated pole which is the witness to their strength of beak and perseverance. The explanation of the singular attack is that the birds, hearing the vibration of the wires as they tremble in the wind, mistake it for the hum of insects within the post, and courageously peck their way into the coveted feast. It matters not whether the timber is fresh or old; and I have been assured by a Norwegian telegraph engineer, that he has found several newly erected posts perforated in a single night. Bears in the mountain districts are also said to attack the foot of the posts, tooth and nail, under the impression that there are bees within; and after the experiments of Mr. C. V. Boys on the influence of tuning forks on spiders (see NATURE, vol. xxiii. p. I49), the deception of these animals is quite intelligible. The authenticated fact that wolves are scared away from whole districts in Norway on the appearance of a telegraph line there, is not so easily understood, unless it be that the wires are held to be some kind of snare. This explanation is supported by the custom of Norwegian farmers of running a cord on poles round their homesteads to keep off the wolves, and it is stated that an entire peninsula was kept clear of wolves by spanning its neck in this fashion. 
The War Office exhibit, which, in the face of flattering expectations, and in spite of interested accounts, must be pronounced a very disappointing one, and comparatively insignificant when contrasted with the display made by foreign governments in Paris, has nevertbeless a novel feature in the equipment of a mountain telegraph train for service in the field. This is carried by three dummy mules, one of which bears two drums containing about three miles of insulated wire for laying on the ground, another bears the working tools, and a third the sheltertent, furniture, and apparatus, constituting the mountain of fire. "Sounders" are used in preference to "inkers" as receiving instruments, and telephones are added, because when a wire is cut by the enemy, or otherwise

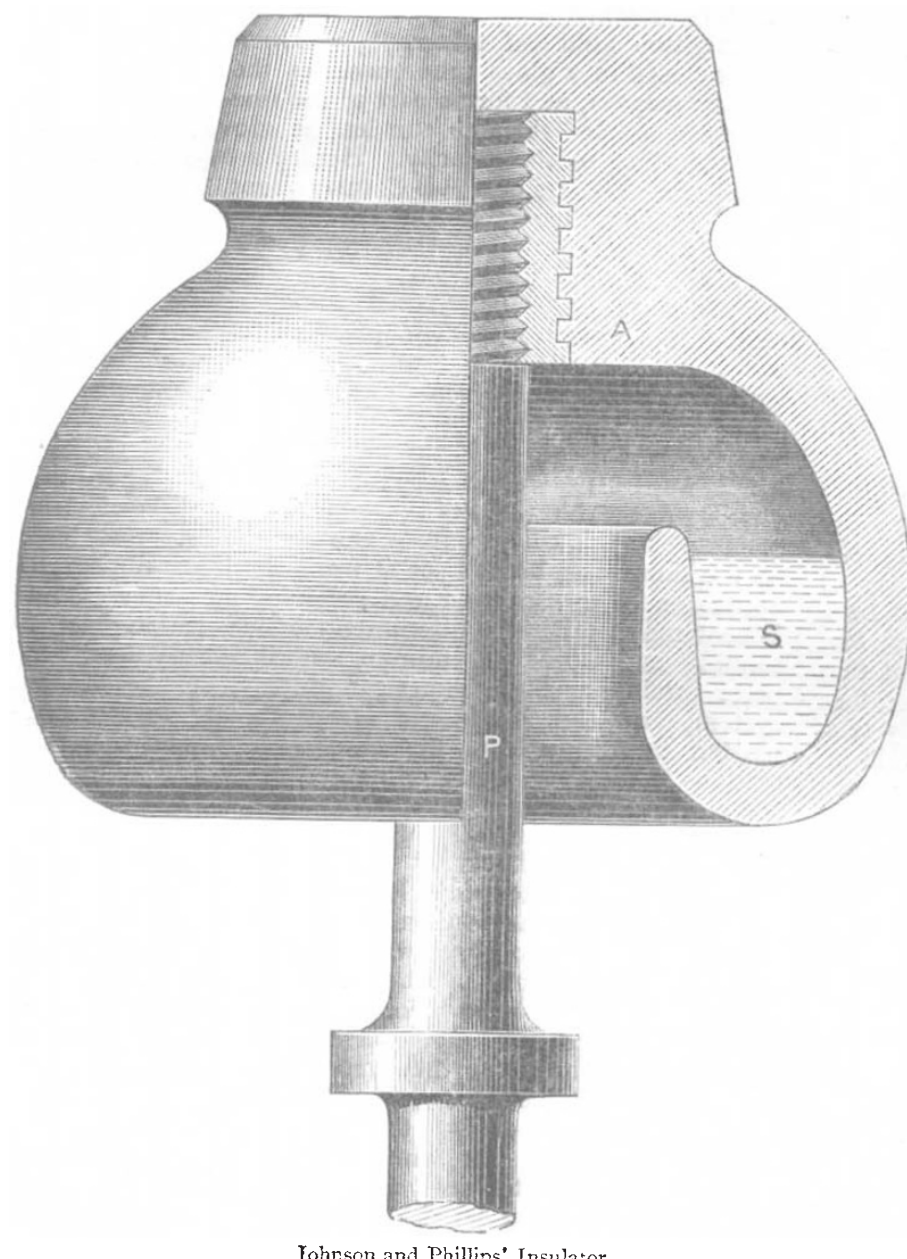

Johnson and Phillips' Insulator.

damaged, the telephone will often read a message when no other instruments will. Experiments at Aldershot, and recent experiences in Caffraria, have proved that a telephonic message can be received, thoush the wire is cut and lying on the ground. As an aid to military telegraphy in a difficult country possessing a brilliant sun, the War Office also exhibit a Mance heliograph, or adjustible mirror, for flashing a beam of light in signals, accorling to the Morse telegraphic code. The great advantage of this apparatus is that there is no wire which can be cut by the enemy, and little or no delay in erecting a sending-station. In the recent campaigns of Afghanistan and Zululand it has proved of great service to the army, and messages have been flashed over distanzes varying from forty to sixty miles.

Railway signalling from its earliest infancy is admirably illustrated by the stall of the South-Eastern Railway Company, whose engineer, Mr. C. V. Walker, F.R.S., was one of the first to see the importance of the telegraph for the prevention of accidents and the furtherance of trafflc. Mr. Walker's original electromagnetic semaphore, now used in block signalling, his plan for intercommunication between passengers and guards, and his train. describer for announcing to the next station the character of the approaching train, are all worthy of close attention. Mr. Spagnoletti's apparatus, as used on the Great Western Railway, including his indicator for showing if a lamp is "in " or "out," is also very interesting. So, too, is the new system of Messrs. E. K. Winter and Craik, for working single lines on the block system, and now employed with great success in India. By this arrangement, a train leaving station $\mathrm{A}$ for station $B$ itself puts the outdoor signal at $A$ ?to danger, and this signal remains unalterable by either signalman of himself, until the arrival of the train has been signalled from $B$ to $A$, and "line clear" has again been asked for and obtained. Models of the Preece system, as worked on the London and South-Western Railway, the Sykes' combined lock and block system, as used on the Metropolitan District, and other railways, and Harper's interlocking instruments, as employed by the London, Brighton, and South Coast, and other Railways, are also exhibited. This company likewise shows the Saxby and Farmer Union of Lock and Block Signalling, and many other things, including Perry and Houghton's alarm for tunnels, together with alarm-bells for gatehouses or level crossings. The electric fog and night signal of Mr. E. A. Sullivan is worthy of note. By this the wheel-tire of a passing train is made to press down a lever and sound a gong, but the gong can only ba sounded when the signalman liberates the lever by electromagnetism. In King's Electric Railway Signal (exbibited by the Electric Railway Signalling Company of Stone Cross, Notts), there are signal posis placed at intervals along the line, and the train passing the first of these puts the signal, by mechanical means, at danger, while at the same time it signals forward by means of electricity to any distant junction. On passing the next post, it puts the signal at danger, and sets the post just past at line clear. At junctions the signals are connected with the points, which, when opened, show danger to the driver coming on the main line, and clear to the branch, remaining so until the points are closed.

The English firm of Siemens Brothers, Charlton, exhibit a number of portable field outpost telegraphs, with sounders and inkers; such as are used in the German army. Jointers' tools, A B C instruments, and other ordinary telegraphic apparatus, is also displayed, including specimens of their compound telegraph wire, made by covering steel wire with a skin of copper, to increase the electric conductivity and non-rusting qualities. Siemens' telegraph poles made of wrought-iron tubes inserted into cast-iron tubular bases, are also exhibited, together with Le Grand and Sutcliffe's base pile for sinking into the ground, to form a root for the pole. The great weight of this pole is, however, against it, for use abroad, where, owing to the ravages of the white ant, iron poles are preferable to wooden ones. Weight is an important item when transport has to be considered in a new country, and hence the lighter pole of Mr. J. Muirhead (as exhibited by Messrs. Latimer, Clark, Muirhead, and Co.) has advantages in this respect. It consists of a light iron tube, strengthened below by a steel lining. and inserted 
in a cast-iron socket, which is flanged vertically to give great strength combined with lightness. The cast.iron socket has a small, flat base plate, which enters the ground, but the lateral resistance of the pole is chiefly due to the radial position of the vertical flanges, which press upon an ever-increasing section of the surrounding soil. Messrs. Latimer, Clark, Muirhead, and Co. exhibit a great variety of telegraphic apparatus, part made by themselves, and part by the Western Electric Manufacturing Company of Chicago. Certain of the American sounders are mojels of neat workmanship and compact device. While upon the subject of sounders, which are the most promising of telegraphic receivers at present, we may mention the bell-sounder of Sir Charles Bright, exhibited on the stall of Mr. E. B. Bright, C.E. The hammer of this ingenious little instrument strikes upon two musical brass tubes of different pitch. and so gives out a much pleasanter sound than the tapping of the ordinary sounder.

The number of wire and cable manufacturers who exhibit at the Crystal Palace is considerable, and there are signs of great activity in this department, especially for telephonic and electric lighting purposes. We have only to deal with land lines at present, and may mention the excellent specimen of galvanised iron telegraph wire exhibited by Messrs. Johnson and nephew, and $\mathrm{Mr}$. Walter T. Glover, of Manchester, and others. The chief novelty in land wires is the use of phosphor bronze for telephonic lines. This alloy is very strong and conductive, so that much smaller wires are required than when iron is used. Moreover, it withstands the chemical action of atmosphere better, and is less exposed to storms. Its use, however, has not become at all general; and this is partly due to its great elasticity, rendering it difficult to put up. Specimens of this wire are shown by the Phosphor Bronze Company, of Sumner Street, London.

In insulators the pattern exhibited by Messrs. Johnson and Phillips is deserving of notice. As illustrated in the figure, it consists of a porcelain bell $A$, curved inwards to form an oil-well $\mathrm{S}$, which is filled with a fluid insulator, such as paraffin. $P$ is the bolt of the insulator, which supports it from the bracket of the pole. As a film of dew or rain cannot form on the surface of the insulating oil, the insulation resistance of this insulator is said to be many hundred times higher than that given by the ordinary insuiators in use, and what is perhaps of more consequence, it is far more constant.

The tendency of the time is for overhead telegraph wires to give place to underground ones, as they have in Germany. Underground wires are less subject to accident from violence or storms, and hence are easily maintained in good condition. Trunk subterranean lines are about to be lajd in England by the Post Office, and there are signs that the existing telephone lines will ere long have to be superseded by wires laid under the streets. For this purpose the box curb of Mr. W. Reddall, exhibited in the Western Gallery, may be useful. The idea is to make the curb of the pavement in the form of an iron box in proper lengths, and lay the wires in it; the lid being removable at will for inspection. The strong earthenware jointed pipes made by Messrs. Doulton and Co., of Lambeth, for holding subterranean wires, are also worthy of remark.

\section{NOTES}

Prof. E. RAY LANKeSTER, F.R.S., has been appointed to the Chair of Natural History in the University of Edinburgh, in succession to the late Sir C. Wyville Thomson.

THE Senalus Academicus of Edinburgh Univer ity have resolved to offer the honorary degree of Dostor of Laws to $\mathrm{Mr}$. John Simon, F.R.S., late medical adviser to the Privy Council ; Dr. Angus Smith, F.R.S.; and Mr. Joseph Anders n, secretary to the Society of Antiquaries, Edinburyh. The degrees will be conferred with the ordinary examination de grees in arts, seiences, and divinity at the graduation ceremonial to be held on A pril $\mathbf{2 1}$.

The President of the Linnean Society, Sir John Lubbock, held a reception at the Society's rooms at Burlington House on Tue day last. The guests began to arrive at nine o'clock, and were received in the Library by the president and officers. Prominent amongst the objects exhibited was a striking portrait of Mr. Charles Darwin, painted for the Society by Mr. John Collier, and allowed by all to be the best portrait extant of our great naturalist. Carnivorous plants were strongly represented amongst the large contributions of plants from the Royal Gardens, Kew, and the leading nurserymen; in addition there were many fine specimens shown for their ornamental qualities. In the glass cases of the Library there were exhibited manuscripts of Linnxus, and medals struck in his honour; Wedgwood medallions of scien. tific men (lent by Sir Joseph Hooker); a series of caddis-flies, shown by Mr. R. MacLachlin ; dredging apparatus, \&c., by Mr. H. C. Sorby ; new drugs by Mr. Thomas Christy; and Sikkim Rhododendrons, by Mr. J. H. Mangles. In the galleries was placed a series of cases of crustacea and insects, extibited by Mr. I. T. Carrington; and in the Council Room a set of drawings of pollen, made by $\mathrm{Mr}$. Charles White. The rooms were well filled during the evening, and among the visitors were many men distinguished in various departments of science.

THE following are the lecture arrangements of the Royal Institution after Easter :-Mr. E. B. Tylor, four lectures on the History of Customs and Beliefs, on Tuesdays, April I8 to May 9 ; Prof. A. Gamgee, four lectures on Digestion, on Tuesdays, May 16 to June 6 ; Prof. Dewar, eight lectures on the Chemical and Physical Properties of the Metals, on Thursdays, April 20 to June 8 ; Mr. F. Pollock, four lectures on the History of the Science of Politics, on Saturdays, April 22 to May I3; and Prof. J. Masson, on Poetry and its Literary Forms, on Saturdays, May 30 to June Io. The Friday evening meetings will be resumed on April 21, when Prof. Dewar will give a discourse on the Experimental Researches of Henri Ste Claire Deville.

THE fullowing are among the papers announced to be read at the meeting of the Institution of Naval Architects to day and to-morrow :-The revision of the tonnnage laws, by W. H. White; on tonnage measurement and moulded depth in relation to freeboard, by W. W. Rundell ; on the basis for fixing suitable load lines for mercantile steamers and sailing vessels, by B. Martell ; on launching velocities, by W. Denny, F.R.S.E.; on the transverse strains of iron merchant vessejs, by Messrs. P. Jenkins and T. C. Read; on progressive speed trials, by J. H. Bile; ; on curves of stability of some mail steamers, by J. H. Biles; approximate formulæ for the calculation of trim, by M. J. A. Normand; on the reduction of transverse and longitudinal meta. centric curves to ratio curves, by W. Denny, F.R.S.E.

ON Tuesday evening, at the Royal College of Physicians, a large representative meeting of both branche; of the medical professi $n$ was holl, with a view, in face of organised opposition to the prozress of :cientific re:earch, of takin; steps to "bring the leyitimate influence of the medical profession more effectively to bear on the promotion of those exact researches in physiology, pathology, and therapeutics which are essential to sound progress in the healing art." Sir William Jenner presided. The chairman pointea to the fact that at the present time there was no society to guide and protect research, and stated that it was intended to found the proposed society on a broad basis. He declared that it was not proposed to attempt to abrogate the existing law cn research; but it was intended to watch the operation of the law, and to see that there were no delays in important cases. He referred, as an instance of the 